\title{
Development Dynamics Study of Professional and Pedagogical Culture of Communication in Professional Activities of Teachers
}

\author{
Albina R. Shaidullina \\ Almetyevsk State Oil Institute, 423450, Almetyevsk, Russia \\ Email: albina-plus@mail.ru \\ Olga G. Maksimova \\ Chuvash State Pedagogical University named after I.Y. Yakovlev, 428032, Cheboksary, Russia \\ Elena Y. Fadeeva \\ Kazan (Volga region) Federal University, 420008, Kazan, Russia \\ Elmira R. Khairullina \\ Nailya S. Valeyeva \\ Renat N. Zaripov \\ Irina R. Zaripova \\ Kazan National Research Technological University, 420015, Kazan, Russia
}

Nikolai V. Kuzmin

Mari State University, 424000, Yoshkar-Ola, Russia

\section{Doi:10.5901/mjss.2015.v6n2s3p216}

\section{Abstract}

Teachers and students entities interaction implementation in the educational environment of the school requires the high level of professional and pedagogical communication culture formation of modern teachers. In this regard, this article is focused on the dynamics study of teachers professional and pedagogical communication culture development. The results of the experiment presented in the paper show the dependence of psychological and pedagogical components development level of teachers professional and pedagogical culture of communication on external factors - their professional activities experience. The article can be used in the process of professional training and retraining of teachers to form the high level of professional and pedagogical culture of their communication.

Keywords: professional and pedagogical culture of communication, teacher, formation and development, professional competence, components, experience of pedagogical activity.

\section{Introduction}

\subsection{The urgency of the problem}

In the educational process at least usually two entities - learner and teacher participate. And the connecting link in this process is communication. The productivity of pedagogical activity is largely, if not entirely, determined by the level of pedagogical communication technology knowledge of the teacher (Kavdangalieva, 1999; Labutova, 1990; Sakhieva, 2015). The analysis of pedagogical practice shows that many serious difficulties in training and education problem solving arise because of the teachers' inability to organize the communication with children. No matter what kind of training and education methods were used, the teachers' influence on the students' identity is available only through the live and 
direct communication with them. Hence, the importance of teachers' professional and pedagogical communication culture development is very urgent.

Professional and pedagogical culture of communication as a unique characteristic of teachers' professional activity is varied in their manifestations and integrated of communication culture, professional culture, pedagogical culture.

\subsection{Analysis of teachers' survey}

Analysis of the teachers' survey results shows that they are not familiar with the concepts of "professional culture of teachers" and "professional and pedagogical culture of communication", do not have clear ideas about their components, and do not have sufficient command of self-development skills. Professional teaching culture is considered as a "gift of God" by the majority of teachers, it is associated with the inborn qualities of the individual (Slastenin, 2008; Leontiev, 2003).

\subsection{The essence of teachers' professional and pedagogical communication culture.}

Under the professional and pedagogical culture of communication we understand one of the most important characteristics of teachers' professional culture as a coherent system of interrelated psychological and pedagogical components, including communication and organizational skills, empathy, self-control in communication, professionally important personal qualities of a teacher.

The development of professional and pedagogical communication culture as a dynamic multi-functional formation in the structure of teachers' professional culture is carried out in the entities cooperation, which is directed on the students' development as the entities of cognition and communication (Grishnyaeva, 2000; Kavdangalieva, 1999; Telegina, Galimova \& Masalimova, 2015). In this process, the teacher organizes this interaction with the students and the students interaction with cognition subjects, which is an independent process of their cognition of knowledge, of the properties and relations of objects, conditions of their origin and transformation.

\subsection{Literature Review}

Professional and pedagogical communication culture, especially of young teachers, in most studies was seen as something formed at the stage of training or something that requires further formation at the stage of professional retraining. In educational research mainly issues of formation of communicative culture are taken into consideration (Avvo, 1999; Grishnaeva, 2000; Ivanov, 1983; Kavdangalieva, 1999; Kunitsyina, 2001; Labutova, 1990; Mendjeritzkaya, 2001; Sherbakova, 2006; Faller, 2000 and others). Only in a few studies teachers professional communication culture is considered in the context of its entity (Abulhanova, 1994; Leontiev, 2003; Lobanov, 2004; Slastenin, 2008; Slobodchikov, 2013; Shchurkova, 2002 and others). However, the development of professional and pedagogical communication culture as a holistic process that occurs in the entity space of the teacher and the pupil continues to be poorly understood pedagogical phenomenon. In this regard, it becomes relevant to study the process of teachers' professional and pedagogical culture formation in entity interaction.

\section{Materials and Methods}

\subsection{The purpose of the experiment}

The purpose of the experiment was to determine the level of professional and pedagogical communication culture, forming in the process of professional development.

\subsection{The hypothesis of the study}

At the pilot stage a hypothesis was proposed that the development dynamics of teachers' professional and pedagogical communication culture depends on following psycho-pedagogical components development: communication and organizational skills; empathy; self-control in communication; professionally significant personal qualities, including pedagogical objectives, pedagogical thinking, pedagogical orientation, pedagogical reflection, pedagogical tact. 


\subsection{The participants of the experiment}

In the process of ascertaining experiment 610 persons were surveyed, 170 teachers who had 2 years of work experience, 190 - four and 250 teachers - five years of work experience at school.

\subsection{Experiment Methods}

For diagnosis the following methods were selected:

1. The method for communicative and organizational aptitudes assessment by V.V.Sinyavsky and B.A.Fedorishin (1980).

2. Method of evaluation for teachers' ability to empathy by I. M. Yusupov (1994).

3. Methods of self-control assessment in communication by M. Snyder (1987).

4. Assessment method for teachers' professionally important personal qualities by F.G. Mukhametzyanova (2002).

\subsection{The methods' content and focus}

The main criteria when choosing methods were: being high informative; being economical for time necessary to conduct research; being reliable; being ease for implementation. We relied on techniques to get an idea about the level of teachers professional and pedagogical communication culture development through the study of the following psychological and pedagogical components: communicative and organizational skills, empathy, self-control in communication, teachers' professionally important personal qualities.

The chosen methods were used not only for diagnosis of professional and pedagogical communication culture, but also for its development. This fact is very important for a system of personality-centered education. Let's give a brief description of the methods used.

The method for communicative and organizational skills assessment is used to diagnose teachers' potential abilities. It is based on the principle of self-analysis and evaluation test of his behavior features, of organizational and communicative abilities manifestation in different situations. Organizational skills are manifested in the ability to influence people for certain tasks successful solution and specific goals achievement, as well as in the ability operatively understand the "situational interaction of people and direct them to perform social work. Teachers' communication skills are characterized by their ability quickly and easily to establish business and friendly contacts with people, desire to expand the scope of communication, desire to participate in social or group activities, which satisfy people need with a wide, intense communication.

The analysis of the communicative and organizational skills allows us to take into consideration their structure, identify such components, which can be indicators of their respective abilities. The method finds only the actual level of communicative and organizational skills development in a given period of teachers' personality development. They will not remain unchanged in the process of further professional development of teachers. If there is a big motivation, commitment and proper conditions for professional activity the development of these abilities can move to a higher level.

Method for teachers' ability to empathy evaluating by I. M. Yusupov (1994) was designed to study empathy, the ability to put oneself in the other person's position, to arbitrary emotional responsiveness to other people feelings. Empathy is the acceptance of those feelings that are being experienced by one another as if they were our own. Empathy helps to balance the interpersonal relations of the teacher and makes his behavior socially and culturally determined.

Methods of self-control assessment in communication by American psychologist M. Snyder (1987) is used to determine the ability for self-control in communication.

Methods of identification of teachers' professionally significant personal qualities is used to identify the level of such qualities' development as pedagogical tact, pedagogical orientation, pedagogical thinking, pedagogical objectives, pedagogical reflection.

\section{Results}

\subsection{The results of an experiment conducted with teachers, who has 5 years of experience}

In the process of studies, we have obtained the following data. Teachers with experience of 5 years (the sample of 250 people) on the test "Communicative and organizational skills" showed the following results: $24 \%$ have a very high level of 
communication skills' development, $24 \%$ - high, $16 \%$ - average, 16\% below the average, and $20 \%$ - low. In general, the majority of teachers with five years of experience manifests communication skills at the intermediate level.

When studying teachers' organizational skills it was revealed that $28 \%$ of them have a very high level of organizational skills' development, $28 \%$ - high, $24 \%$-average, $20 \%$ - below the average, low level is missing. Thus, teachers with experience of 5 years have well developed organizational skills, which characterize them as entities of communication.

Scores on "Empathy" test show that teachers in this sample have well-developed empathy: $72 \%$ of them have a medium level of empathy development, $4 \%$ - very high and $24 \%$ have high level of empathy development. The low level of empathyis not observed.

On "Self-communication" test the majority of teachers (52\%) have high level of self-control development, $48 \%$ - the average, then, it is fairly well developed self-control. Low self-controlling their communication is not detected.

A high level of pedagogical tact and pedagogical thinking development belongs to $96 \%$ of the teachers, average $4 \%$. All teachers have high level of pedagogical orientation development. A high level of pedagogical goal setting development belongs to $88 \%$ of the teachers, average $-12 \%$. High level of pedagogical reflection development was detected in $92 \%$ of teachers, average - $8 \%$ of teachers. In general, all teachers with experience of five years have high level of all groups of teachers' professionally significant personal qualities development.

Thus, it can be concluded that teachers with five years of teaching activities experience are characterized mainly by high level of professional pedagogical communication culture development.

\subsection{The results of an experiment carried out by teachers with 4 years of experience}

The diagnosis results of teachers with experience of four years (sample 190) revealed that $36.8 \%$ of them have very high level of communicative abilities' development, 10.5\% - high, $26.3 \%$ - medium, 10.5\% - below average and $15.9 \%$ - low. In general, most teachers' communication skills are developed well. Very high level of managerial abilities' development belongs to $5.3 \%$ of teachers, high $-15.9 \%$, medium - 26.3\% and low - 42\%. Test "Empathy" test showed that all the teachers who has fourth years of work experience have an average level of empathy development. Test "Selfcommunication" revealed that the majority of teachers (53\%) have the average level of self-control development, $26 \%$ of them - high and $21 \%$ - low.

The method of "Teachers' professionally significant personal qualities identification revealed that $95 \%$ of the teachers in this sample have high level of pedagogical tact development and the rest of them- average. All teachers demonstrate high level of pedagogical orientation development. High level of pedagogical thinking development was diagnosed in $84 \%$ of teachers and average - $16 \%$ of the teachers. High level of pedagogical objectives development belongs to $79 \%$ of the teachers and average - $21 \%$. Almost all teachers demonstrate high level of pedagogical reflection development (95\%) and 5\% - average. In general, high level of all professionally significant teachers' personal qualities development is found in $95 \%$ of the teachers, and average - in the remaining $5 \%$.

The results generalization of the diagnostic experiment allows us to conclude that the majority of teachers with a four-year experience of pedagogical work shows the average level of professional and pedagogical communication culture development. The most important quality for them is empathy as a manifestation of sensitivity, empathy, compassion for people.

\subsection{The results of an experiment carried out with teachers with experience of 2 years}

The test results of teachers with two years of experience (the sample 170 people) revealed that only $12 \%$ of the teachers have very high level of communicative abilities development, 18\% - high, and 29\% - average, $12 \%$ of teachers - below average and $29 \%$ - low. Very high level of managerial abilities development belongs to $5 \%$ of teachers, high-and middle to $18 \%$, below the average - to $23 \%$, low - to $36 \%$. Most teachers (82\%) have an average level of empathy development, $4 \%$ - high, $6 \%$ - low. More than $65 \%$ of the teachers show the average level of self-control development in communication, $29 \%$ of teachers - high and only $6 \%$ - low.

The testing process revealed that $88 \%$ of teachers have high level of pedagogical tact and pedagogical orientation development, the rest have indicators at the secondary level. Basically, $53 \%$ of teachers have high level of pedagogical thinking development, $47 \%$ - the average. More than $53 \%$ of the teachers have medium level of pedagogical goal setting development, and $47 \%$ - high. High level of pedagogical reflection development belongs to $94 \%$ of the teachers interviewed, the average to the rest.

With summary indicators of separate groups of teachers' professionally significant personal qualities the ratio of 
their competence as an average indicator of all teachers' individual professionally significant personal qualities result was counted. The total score is 5 , which corresponds as high level; from 4 to 3 - average level, then goes low level. The results of the second year teachers' professional and pedagogical communication culture manifestation is presented in table 1.

Table 1. The competence levels of teachers who has 2 years of professional activities experience

\begin{tabular}{|c|c|c|}
\hline Level development & \multicolumn{2}{|c|}{ Competence } \\
\hline & Absolute quantity & $\%$ \\
\hline H & 130 & 76 \\
\hline A & 40 & 24 \\
\hline L & 0 & 0 \\
\hline totally & 170 & 100 \\
\hline
\end{tabular}

Note (here and below) - H - high level of teachers' competence development, A- the average level of teacher's competence development, L- low level of teachers' competence development. An absolute number - the total number of samples.

Table 1 shows, that $76 \%$ of the teachers with two years of work experience have high level of professionally important personal qualities development and $24 \%$ - average, which indicates sufficient capacity for entity interaction.

We also conducted the ranking of professionally significant teachers' personal qualities' group. It was found that teachers with 2 years' experience take the first place on pedagogical orientation, then, almost at the same level, pedagogical reflection and pedagogical tact, and in last place - pedagogical thinking. For teachers with four years' experience in the first place - pedagogical reflection, below - pedagogical tact, then pedagogical orientation and pedagogical thinking, the last place - pedagogical goal setting. Teachers with five years' experience of pedagogical activity take the first place in pedagogical tact, the second - pedagogical reflection, followed by pedagogical thinking, pedagogical orientation, and last place - educational goal setting.

\subsection{Correlation analysis of the components of professional and pedagogical communication culture and competence of teachers with 2 years' experience}

The experimental data were processed by statistical processing. To clarify how some of the communicative culture indicators affect others, or how they relate with them, the technique of secondary statistical processing on the basis of correlation (Pearson, Spearman) and factor analysis were used. Calculation of correlation coefficients between all possible pairs of variables allowed us to obtain a matrix of correlations and relationships of correlation Pleiades (table 2).

Matrix analysis shows that the communicative abilities are significantly correlated with organizational skills (at significance level - 0,99 ) and empathy (at the level of 0.95 ). Organizational skills significantly are correlated with empathy (0.99) and self-control (0.99).

Professional and pedagogical communication culture level expression was significantly correlated with almost all indicators: communication and organizational skills (at significance level with those and other - 0,999), with self-control (at the level of 0.95), which confirms the validity of the test.

Table 2. Correlation matrix of professional and pedagogical communication culture components and teachers competence who has 2 years of experience

\begin{tabular}{|c|c|c|c|c|c|}
\hline Rate & Abilities & empathy & Self-control & competence & Ratio - C \\
\hline C & 0,52197 & 0,3964 & 0,1881 & 0,013 & 0,7987 \\
\hline M & & 0,5558 & 0,5729 & 0,0876 & 0,8402 \\
\hline Empathy & & & 0,3962 & 0,4169 & 0,754 \\
\hline Self-control & & & & 0,057 & 0,4319 \\
\hline Competence & & & & & 0,4418 \\
\hline
\end{tabular}

Note.C-communicativeabilities, M-managerialabilities, Cratio-competenceratio(the sum indicator of professionally significant personal qualities)

The analysis of this correlation matrix shows the relationship between communicative and organizational abilities and 
empathy (at the significance level of 0.95). Professional pedagogical communication culture was significantly correlated with communication skills (at level of significance 0,999 ) and empathy (at the significance level of 0.95 ). Thus, empathy is the general factor of professional and pedagogical communication culture forming of teachers with two years experience (table 3).

Table 3. Correlation matrix of professionally significant teachers' personal qualities and competence (2 years' experience)

\begin{tabular}{|c|c|c|c|c|c|c|}
\hline Ratio & PT & PO & PTh & PGS & PR & competence \\
\hline PT & & 0,7067 & 0,3267 & 0,4885 & 0,6421 & 0,8206 \\
\hline PO & & & 0,5427 & 0,4368 & 0,4954 & 0,8194 \\
\hline PTh & & & & 0,6523 & 0,5083 & 0,7433 \\
\hline PGS & & & & & 0,6331 & 0,7869 \\
\hline PR & & & & & & 0,8151 \\
\hline
\end{tabular}

Note. PT-pedagogicaltact, PO-pedagogicalorientation, PTh-pedagogicalthinking, PGS-pedagogicalgoalsetting, PRpedagogical reflection.

From the correlation matrix (table 3) we can see that pedagogical tact significantly is correlated with pedagogical orientation, pedagogical reflection, competence (level of significance 0,999 ) and pedagogical goal setting (at the level of 0.95). Pedagogical orientation is significantly correlated with pedagogical thinking (0.99), with pedagogical goal setting, pedagogical reflection (at the level of 0.95 ) and competence (level 0,999). Pedagogical thinking is significantly correlated with pedagogical reflection (0.99), with pedagogical goal setting and competence (level 0,999). Pedagogical goal setting is significantly correlated with pedagogical reflection and competence (level 0,999). Selected correlations indicate the formation of teachers' professional and pedagogical culture based on the optimal combination of different groups of professionally significant teachers' personal qualities, each of which firstly manifests itself, and only then is formed.

\subsection{Correlation analysis of professional and pedagogical communication culture components and professionally significant personal qualities of teachers with 4 years' experience}

We also revealed (see table 4) correlation between professional and pedagogical communication culture and separate groups of professionally significant personal qualities, which showed the strongest relationship between the professional and pedagogical communication culture and pedagogical thinking.

Table 4. Correlation matrix of professional and pedagogical communication culture components (teachers with experience of 4 years)

\begin{tabular}{|c|c|c|c|c|c|}
\hline Ratio & $\mathrm{M}$ & Empathy & Self-control & Competence & PPCC \\
\hline $\mathrm{C}$ & 0,69 & 0,2061 & 0,159 & 0,2353 & 0,93 \\
\hline $\mathrm{M}$ & & 0,4557 & 0,4556 & 0,3996 & 0,8618 \\
\hline Empathy & & & 0,2512 & 0,1876 & 0,4557 \\
\hline Self-control & & & & 0,23 & 0,263 \\
\hline Competence & & & & & 0,3665 \\
\hline
\end{tabular}

Note. PPCC - professional and pedagogical communication culture, C-communicative abilities, $\mathbf{M}$-managerial abilities.

Analysis of the correlation matrix presented in table 4 shows that communication skills of teachers with years' experience are significantly correlated with their organizational abilities (on level - 0.99). In turn, their organizational skills are significantly correlated with empathy (at the significance level of 0.95 ) and competence (level of 0.95). Communicative culture is significantly correlated (see figure 3) with the communicative and organizational skills (level 0,999), empathy (at the level of 0.95 ). From the diagram in Fig. 3 we can see that organizational skills are a common factor in the expression and formation of communicative culture. Analysis of the correlation matrix presented in table 5 shows that pedagogical tactics significantly correlated with pedagogical goal setting and competencies (level 0,999), with pedagogical reflection (on level 0.99 ). Pedagogical orientation is significantly correlated with competence (level of significance -0.99 ). 
Table 5. Correlation matrix of professionally significant personal qualities (teachers with 4 years' experience)

\begin{tabular}{|c|c|c|c|c|c|c|}
\hline Ratio & PT & PO & PTh & PGS & PR & Competence \\
\hline PT & & 0,3381 & 0,2758 & 0,7699 & 0,5831 & 0,8271 \\
\hline PO & & & 0,1279 & 0,4246 & 0,3545 & 0,5759 \\
\hline PTh & & & & 0,3749 & 0,3993 & 0,5767 \\
\hline PGS & & & & & 0,6244 & 0,8801 \\
\hline PR & & & & & & 0,7996 \\
\hline
\end{tabular}

Note. PT - pedagogicaltact, PO - pedagogicalorientation, PTh - pedagogicalthinking, PGS - pedagogical goal setting, PR pedagogical reflection.

Pedagogical thinking (PTh) was significantly correlated with competence (level of significance 0.99 for 17 degrees of freedom). Pedagogical goal setting was significantly correlated with pedagogical reflection (at the significance level 0,99) and competence (level 0,999). Pedagogical reflection was significantly correlated with competence (level 0,999).

Correlation analysis of professional and pedagogical communication culture components and professionally significant personal qualities of teachers with 5 years' experience.

Pedagogical tact, pedagogical goal setting, and pedagogical reflection are the common factors of teachers' professional and pedagogical culture formation.

Table 6. Correlation matrix of professional and pedagogical communication culture components (teachers with 5 years' experience)

\begin{tabular}{|c|c|c|c|c|c|}
\hline Ratio & A & Empathy & Self-control & Competence & PPCC \\
\hline C & 0,5657 & 0,4910 & 0,2827 & 0,0165 & 0,7414 \\
\hline M & & 0,0626 & 0,2864 & 0,3990 & 0,4371 \\
\hline Empathy & & & 0,2732 & 0,221 & 0,5771 \\
\hline Self-control & & & & 0,1625 & 0,1622 \\
\hline Competence & & & & & 0,1264 \\
\hline
\end{tabular}

Note. PPCC-professional and pedagogical communication culture, C-communicative abilities, M-Managerial abilities, A abilities.

In study results' processing correlations between teachers' professional and pedagogical communication culture and separate groups of professionally significant personal qualities are found, which showed the strongest relationship between the professional and pedagogical communication culture and pedagogical tact.

Correlation matrix analysis presented in table 7 showed that pedagogical tact was significantly correlated with the pedagogical orientation, pedagogical thinking, pedagogical goal setting and competence (level 0,999).

Pedagogical orientation was significantly correlated with pedagogical thinking (at the significance level of 0.99 ), with the pedagogical goal setting and competence (level - 0,999), with pedagogical reflection (at a significance level of 0.95). Pedagogical thinking was significantly correlated with the pedagogical goal setting and competence (level of significance 0,999), with pedagogical reflection (0.99). Pedagogical goal setting was significantly correlated with pedagogical reflection (level - 0,999) and competence (0.99). Pedagogical reflection was significantly correlated with competence (level 0,999).

Table 7. Correlation matrix of professionally significant personal qualities of the teachers with 5 years' experience

\begin{tabular}{|c|c|c|c|c|c|c|}
\hline Ratio & PT & PO & PTh & PGS & PR & Competence \\
\hline PT & & 0,8893 & 0,7751 & 0,8527 & 0,4716 & 0,9971 \\
\hline PO & & & 0,6672 & 0,8016 & 0,5267 & 0,8909 \\
\hline PTh & & & & 0,7769 & 0,5423 & 0,8744 \\
\hline PGS & & & & 0,6393 & 0,9469 \\
\hline PR & & & & & & 0,7111 \\
\hline
\end{tabular}

Note. PT - pedagogicaltact, PO - pedagogicalorientation, PTh - pedagogicalthinking, PGS -pedagogical goal setting, PR pedagogical reflection.

This table indicates that the pedagogical orientation, pedagogical thinking and pedagogical goal setting are manifested as 
a general factor of competence for teachers with experience of 5 years. Also the correlation between professional pedagogical communication culture and separate professional groups of significant personal qualities are found, which showed the strongest relationship between professional pedagogical communication culture and pedagogical thinking.

\section{Discussions}

Experimental study of formation dynamics of professional and pedagogical communication culture separate structural components allowed us to detect general factors in the development of teachers' professional and pedagogical communication culture with different experience of professional activity. They are for teachers with experience of 5 years are empathy, pedagogical orientation and pedagogical tact. For teachers with experience of 4 years - self-control in communication, pedagogical reflection. For teachers with experience of 2 years - communicative and organizational abilities, pedagogical goals setting, pedagogical thinking.

After carrying out diagnostics on all indicators of professional and pedagogical communication culture psychopedagogical components the total (average of indicators taking into account standard deviations) ratio was counted and a number of teachers estimated (in percentage) classified according to level characteristics to one or another level of professional and pedagogical communication culture formation.

The diagnostic results showed that the formation of teachers' professional and pedagogical communication culture is a dynamic development process as of separate psychological-pedagogical components so their interrelationships and interdependence associated with the experience of pedagogical activity and the use of a particular model entity interaction.

The development of professional and pedagogical communication culture among the teachers with experience of two years is mainly at the secondary level (64.7\%). Communicative and organizational abilities are found among most teachers at high level, empathy - low, the self-control in communication - on average, and professionally important personal qualities of most teachers are found at the secondary level. As for teachers' professionally significant personal qualities among the teachers who has two years of work experience the pedagogical orientation is on the first place, then goes pedagogical reflection, pedagogical goals setting, pedagogical tact, and in the last place - pedagogical thinking.

Most teachers with four years of experience have their professional and pedagogical communication culture at average level (52.6\%). However, there is a reduction in the number of teachers exhibiting low level (5.3\%) and increased the number of teachers having high level (42.1\%) of professional and pedagogical communication culture. For this group of teachers their pedagogical reflection is on the first place, next - pedagogical tact, then pedagogical orientation and pedagogical thinking, the last place belongs to pedagogical goal setting.

In the sample of teachers with experience of five years, $48 \%$ of surveyed shows the average level of professional and pedagogical communication culture, $52 \%$ - high, a low level is not detected. For teachers with experience of 5 years the pedagogical tact is on the first place, on the second - pedagogical reflection, then pedagogical thinking, pedagogical orientation, and in last place -pedagogical goal setting.

Formation dynamics of teachers' professional and pedagogical communication culture, studied on the basis of cross sections, is oriented towards a gradual increase of all indicators from low to medium. More significant changes are observed in the increase in the number of teachers with high level of this characteristic. However, only in the fifth year of professional activity the number of teachers, showing a fairly high level of professional and pedagogical communication culture is increased.

\section{Conclusions}

Thus, the results of correlation analysis revealed that among teachers with experience of two years the communication abilities are correlated with the empathy and organizational abilities, which, in turn, are correlated with self-control in communication. Among teachers with experience of 4 years their communication abilities are correlated with organizational abilities, which significantly are correlated with empathy and competence. As for teachers with experience of 5 years - they are characterized by close relationship of communicative abilities with organizational ones and empathy.

The results of factor analysis suggests that such structural psycho-pedagogical components of teachers' professional and pedagogical communication culture, as communicative and organizational abilities, empathy, selfcontrol, communication and a group of professionally significant qualities (pedagogical goal setting, pedagogical thinking, pedagogical orientation, pedagogical reflection and pedagogical tact), are revealed depending on the experience of professional activity and interconnected.

For teachers who have experience of two years, empathy is the general factor in the development of 
communicative, organizational abilities, self-control in communication and professionally significant personal qualities. For teachers with experience of four years the general factor is their organizational abilities. Teachers with experience of 5 years their pedagogical orientation, pedagogical thinking and pedagogical goal setting manifest themselves as general factors not only of individual components of professional and pedagogical communication culture, but also of their competence in general. Teachers of this sample are also characterized by interdependence between their professional and pedagogical communication culture and separate professional groups of significant personal qualities, especially between professional and pedagogical communication culture and pedagogical thinking.

\section{References}

Abulkhanova, K. A. (1994). Social thinking person: challenges and strategies of psychological research. Psychology: 4, 39-55.

Aksenova, G. I. (1998). Formation of a subject position of the teacher in the process of training (Doctoral dissertation). Moscow, 1998. 411.

Aksenova, G. I., Kuptsov, I. I., \& Aksenov, A. N. (2000). Subject and education. Ryazan, 97.

Avvo, B. V. (1999). The possibility of the school as the educational system in enhancing the professional competence of teachers. St. Petersburg, 18.

Fedorishin, B. A. (1985). The system of professional information in high school. Kiev: Radyanska School, 70.

Fetiskin, N. , Kozlov, V. V., \&Manuylov, G. M. (2005). Sociopsychological diagnosis of personality development and small groups. Moscow: Publisher Institute of Psychotherapy, 490.

Fuller, G. A. (2000). Formation of communicative abilities of future primary school teachers. Thesis. Tula.187

Grishnyaeva, I. V. (2000). Formation of communicative culture at the future teachers of preschool education. Novgorod, 21.

Ivanova, T. V. (1983). Features of development of psychological readiness of students to teaching(Doctoral dissertation). Moscow, 204.

Kavdangalieva, M. I. (1999). Pedagogical functions of speech activity a teacher. St. Petersburg, 18.

Kunitsyna, V. N., Kazarinova, N. V., \& Pogol'sha, V. M. (2001). Interpersonal communication. St. Petersburg.

Kushner, Y. Z. (2001). Methodology and methods of pedagogical research. Moscow: MSU, 66.

Labutova, I. V. (1990). Development of general communication skills of students in the conditions of intensive foreign language teaching. Moscow, 18.

Leont'yev, D. A. (2003). Psychology of meaning: the nature, structure and dynamics of the sense of reality. Moscow: Meaning, 487.

Lobanov, A. A. (2004). Fundamentals of Professional Education of communication. Moscow.

Mendzheritskaya, Y. A., Breus E. D., \& Labunskaya, V. A. (2001). Psychology hindered communication: Theory. Methods. Moscow: publishing center "Academy", 288.

Mukhametzyanova, F. G. (2002). Subjectivity student teacher training (Doctoral dissertation). Yelabuga, 382.

Raygorodskiy, D. Y. (1998). Practical psychological testing. Techniques and tests. Samara Publishing House "Bahr", 672.

Sakhieva R.G., Khairullina E.R., Khisamiyeva L.G., Valeyeva N.Sh., Masalimova A.R. \& Zakirova V.G. (2015). Designing a Structure of the Modular Competence-Based Curriculum and Technologies for Its Implementation into Higher Vocational Institutions. Asian Social Science, Vol. 11, No. 2, 246-251, doi:10.5539/ass.v11n2p246.

Shcherbakova, T. N. (2005). Psychological competence of the teacher: content, mechanisms and modalities of development. Rostov.

Shcherbakova, T. N. (2006). Psychological competence of teachers: Acmelogical analysis (Doctoral dissertation). Rostov, 457.

Shcherbakova, T. N., \& Ganieva, A.D. (2006). Teacher and translator as a carrier of subjectivity. Rostov.

Shchurkova, N. Ye. (2002). The key issue of education and professional training subject. Moscow: VentanaGraf, 105.

Sinyavsky, V. V., \& Fedorishin, B. A. (1980) Profconsulting work with high school students. Kiev.

Slastenin, V. A.. Isayev, I. F, \& Shiyanov, Y. N. (2008). Pedagogy. Moscow: Publishing Center "Academy", 576.

Slobodchikov, V. I. (2010). Anthropological perspective of national education. Moscow.

Slobodchikov, V. I. (2013). Key categories of thinking professional teacher . Moscow.

Snyder, M., \& DeBono, K. (1987). Understanding the functions of attitudes: Lessons from personality and social behavior. Hillsdale, New Jersey: Erlbaum, 339-359.

Telegina N.V., Galimova E.G \& Masalimova A.R. (2015).The Structure and Content of the Model of Pedagogical Conditions Binary Approach to Optimization of Control and Diagnostic Functions in Teaching "General pedagogy" to Students. Asian Social Science, Vol. 11, No. 1, 364-368, doi:10.5539/ass.v11n1p364.

Yusupov, I.M. (1994).Psychology of empathy (Doctoral dissertation). St. Petersburg, 252. 